\title{
Strange spaces: a rationale for bringing art and artists into the planning process
}

Jonathan Metzger

Division of Urban and Regional Studies/Department of Urban Planning and Environment Royal Institute of Technology/KTH

\section{ACCEPTED FOR PUBLICATION IN PLANNING THEORY, CHECK PRINTED PLANNING THEORY FOR FINAL VERSION OF THE TEXT}

\begin{abstract}
The purpose of this article is to offer a rationale for bringing art and artists into the planning process. Although there appears to exist a nascent interest in planner-artist collaborations in contemporary planning practice and research, accounts of such collaborations in planning literature are generally patchy and often under-theorized. In this article I argue that art and artist-led activities can function as a powerful vehicle of communication in the planning process. The unique potential of planner-artist collaborations is based on the artistic license that grants the artist a mandate to set the stage for an estrangement of that which is familiar and taken-for-granted, thus shifting frames of references and creating a radical potential for planning in a way that can be very difficult for planners to achieve on their own.
\end{abstract}

In Swedish, the noun for "art", konst, derives from the same linguistic root as the adjective "strange", konstig. Commenting on the contemporary debates about the societal value of art, the Swedish artist Lars Nilsson plays on this double meaning when he says that "Art [konst] must never be useful, art must be allowed to be artful/strange [konstig]". ${ }^{1}$ In his comment, Nilsson enacts the commonly posited binary opposite between utility and artistry, staging these terms as mutually excluding opposites. In this article I will on the contrary argue that art and artist-led activities in fact can be very useful, and actually function as a powerful vehicle of communication in the planning process, precisely because of the artistic license that grants the artist a mandate to set the stage for an estrangement of that which is familiar and taken-for-granted, thus shifting frames of references and creating a radical potential for planning in a way that can be very difficult for planners to achieve on their own. In short, one could say that my purpose in this regard is to shift focus away from

\footnotetext{
${ }^{1}$ Quoted by Sachs in KK-bladet (4)2007: http://www.kk-stiftelsen.com/upload/publikationsfiler/kk_bladet/KKbladet-4-2007-publ.pdf
} 
discussions about "art in the public sphere" to instead try to generate a discussion on art as a public sphere.

Although there appears to exist a nascent interest in planner-artist collaborations in contemporary planning practice and research, accounts of such collaborations in the planning literature are generally patchy and often under-theorized. Therefore I hope that the theoretical discussion concerning potential gains of planner-artist collaborations that is provided in this article can be used as a platform to motivate a furthering of artist involvement in planning processes at all administrative levels. It is important to point out that I have no pretension of being exhaustive in my analysis of planner-artist collaborations, as the field of potential gains and risks concerning this type of cooperation is vast and merits much further exploration than what can encompassed within the scope of this article. Here I will simply focus upon an in-depth discussion of one of many ways to realize the potentials of this type of collaboration. The theoretical ideas presented in the article will also be further developed and discussed in relation to empirical material gathered in the aftermath of a pioneering art/planning project undertaken by artists and regional planners as part of the process to formulate a new regional development plan for the Stockholm region, RUFS $2010 .^{2}$

The text is structured in four sections. The first section contains an overview of the contemporary discourse on the role of culture and art in relation to spatial planning. The second section sketches the outlines of a potential role for art in the practice of spatial planning, with a focus upon collaborative planning regimes. The third section describes the case-study concerning artist involvement in the process to create a new regional development plan for the Stockholm region,

\footnotetext{
${ }^{2}$ As the author of this text, I wish to be clear that I am a non-subscriber to the idea and ideal of impartial observation, and that $I$ as a researcher have no ambition to foster any form of illusion of having been an impartial or passive observer in the concrete artist-planner collaboration project that is being discussed in this article. Rather, I was actively involved in the development and implementation of said project while serving as a practicing planner at the Stockholm County Council Office of Regional Development and Public Transportation. The research behind this paper is thus based in part on participatory observation, but also on in-depth post-project interviews and recorded group discussions with participants in the workshop project discussed in the paper (including artists as well as planning staff and workshop participants), as well as additional materials such as project management log-books.
} 
RUFS 2010. The fourth and final section provides a closing discussion and a brief outlook towards possible directions for future research.

\section{Culture and/in spatial planning}

Culture, and specifically the role of culture in spatial planning and place development, has been a hot topic within planning research and practice during the past decade or so. The role of spatial planning for promotion of culture and the arts has been (more or less critically) discussed by Landry (2000), Evans (2001), Markusen \& King (2003), Florida (2005), Kunzmann (2004) Jensen (2007) and Young (2008), among others. Whether the authors focus on culture as an economic driver, as in Florida's perception of the "creative class" and their preferences, or write from a broader, more humanistic perspective such as Evans or Kunzmann, or even from a more critical perspective such as Jensen's, the discussion generally focuses on the question of what planners can do to develop cultural capacities in different localities such as regions or cities (cf. Gray, 2004: 42). With a different wording, the area of interest appears to be planning for culture. In this article I will attempt to turn this established perspective upon its head and ask not what planning can do to enhance the development of culture and the arts, but rather discuss the potential inherent in artistic practice to develop the practices of spatial planning. What in other words could be described as planning with culture, that is - the utilization of art as a planning tool and artists as partners in the planning enterprise. To be even rasher: to ask not what planners can do for culture and art, but what can culture and art do for planners. ${ }^{3}$ The task I set before myself is to show how cultural professionals, in my specific case artists - can provide useful help in invigorating common bureaucratic forms of planning.

\footnotetext{
${ }^{3}$ Bauman (1973) has noted that "culture" is one of the most over-defined and contested concepts in use, and this was an observation made almost forty years ago, before the full impact of the so called "cultural turn" in the social sciences. To attempt to skirt the never ending debate on the proper definition of culture as a concept - a debate which there is no room to elucidate or develop within the framework of this article - it is perhaps best to simply clarify that in this article, the usage of the term "culture" is not derived from the basic anthropological understanding of the concept, where it is used to signify the full scope of human, symbolic production. Rather the term is used in a manner that is closer related to Bourdieu's (1993) concept of "the field
} 
For sure, I'm not the first to be interested in this possibility. For instance cultural planning-advocates Bianchini \& Santacatterina (1997: 84-85) propose that the method of cultural planning must be seen as a holistic approach to invigorate urban planning and policy through cultural awareness rather than simply "planning for culture". Young (2008) pleads for what he terms the "culturization" of planning, which can be read as an increased awareness of the merits of integrating culture into planning practice, although he does not specifically mention planner-artist collaborations as a means to achieve said culturization. Sandercock $(2004,2005)$ on the other hand specifically engages with the issue of planner-artist collaborations as a means of broadening the horizon of planners and developing contemporary planning practice. Sandercock has also edited a theme section of the journal Planning Theory \& Practice (Sandercock, 2005), where planning consultant Wendy Sarkassian tells the story of her experience of a planner-artist collaboration in a community renewal project in Brisbane, Australia (Sarkassian, 2005), an account which is then reflected upon and related to by other planning practitioners (Landry, 2005; Gordon, 2005; Dang, 2005; Shaw, 2005). Although the latter accounts provide valuable stories of practice, all the above mentioned accounts depict a planning reality where initiatives to involve art and artists in the planning enterprise generally are local, isolated and patchy.

Except for the writing of Sandercock, there appears to be a lack of comprehensive theoretical reasoning concerning the potential merits and drawbacks of involving artists in planning processes, notwithstanding the growing academic interest on the roles, potentials and functions of art in urban landscapes and the built environment in related fields such as human geography, urban studies and architecture (see for instance Kwon, 2004; Miles, 1997, 2004; Pinder, 2005, 2008; Rendell, 2006). Both Sandercock $(2003,2004)$ and Hillier $(2002,2007)$ have used art analogies to expand our mode of thinking about planning theory and practice, but neither of them suggests any concrete measures as to how the analogies between art and planning can be put into concrete practice in the form of

of cultural production", which forms a context wherein "art" can be seen as an amorphous and fluid term that is most easily operationally defined as "that which artists do". 
planner-artist collaborations within planning processes. Thus, the question of what, and how artists can provide valuable input into planning processes, is still largely left begging. It remains to be explored how planner-artist collaborations can function within all levels of spatial planning, including national and supra-national levels, all the way down to the regional (as in my empirical example) and local community levels. Further, frameworks for more long-term and structural artist involvement in planning processes, rather than just local ad-hoc project initiatives also need to be examined.

\section{A rationale for bringing artists into the planning process}

The two most dominant contemporary planning paradigms, which are often referred to as the neomodern and the post-modern paradigms, both highlight the need to open up planning processes to new voices and new perspectives. In one of the central texts of the neo-modern (collaborative/communicative/deliberative) paradigm, Healey (2006) calls upon stakeholders to

“...take a major leap in reflexive activity, to stand back from their particular concerns, to review their situation, to re-think problems and challenges, to work out opportunities and constraints, to think through courses of action which might be better than current practices and to commit themselves to changing things" (Healey, 2006: 244). Further, the frames of reference within which issues are discussed and decisions taken must be "re-shaped", which requires that participants in planning processes must "shift the systems of meaning about a set of problems which they have used in the past" (Healey, 2006: 244). Healey further refers to this process as the "opening out" of issues, a "mental 'unhooking' from previous assumptions and practices, to try to see issues in new ways" (Healey, 2006: 272).

In a similar vein, in her (2002) article Sandercock, often labeled as one of the central representatives of the post-modern planning paradigm, notes that one of the major transformations planning practice needs to go through to continue developing into the $21^{\text {st }}$ century is to develop the ability to "imagine oneself in a different skin, a different story, a different place, and then desire this new self and place that one sees" (Sandercock, 2002: 8). Further, she writes that planners and citizens need to 
"suspend [our] habits of being and come out in the open and engage in dialogue with strangers" (Sandercock, 2002: 8). Hillier (2002) also discusses Benhabib's (1992) “interactive universalism" where "participants are able to take up the perspective of the other and develop an 'enlarged mentality', a sensitivity to, and appreciation of, the wide range of moral considerations which are relevant in particular circumstances" (Hillier, 2002: 41). In another text (Hillier, 2007), Hillier also highlights the ubiquity of clichés, the "ready-made perceptions" that inform and guide the actions of planning stakeholders, and the need to free the "social imagination" in planning processes from such clichés for the exercise of planning to truly live up to its potential to change society (Hillier, 2007: 223).

Unfortunately, experience shows that the achievement of this openness towards Others and Other futures within planning processes is most often easier said than done (see, among others Flyvbjerg, 1998; Hillier, 2002; Plöger, 2004; March \& Low, 2004; Kaza, 2006; Brand \& Gaffikin, 2007). As in all processes where important material and symbolic resources are at stake, planning processes are inherently fraught with strife that can not simply be brushed over through forced-through consensus constructing activities that often amount to little more than "consensus steering" (Plöger, 2004). When consensus is really built from the bottom and upwards among stakeholders, the quest for unanimous "buy-in" into the plan from all involved stakeholders often leads to what Brand \& Gaffikin (2007) call "empty signifiers": "very low common denominators to which most stakeholders could acquiesce without the cost of resource commitment and delivery" (Brand \& Gaffikin, 2007: 303). This, according to Brand \& Gaffikin, leads to nothing more than a refinement of "the craft of cosmetic conflict suspension" among stakeholders (Brand \& Gaffikin, 2007: 304), which perhaps can be understood as something similar to Kaza's "pragmatic consent" (Kaza, 2006: 259), but quite short of the deep mental unhooking and suspensions of habits described above by Healey and Sandercock.

Concomitant to this, stakeholders involved in planning processes will also often be prone to strategic posturing through misrepresentation or exaggeration of own positions and preferences to gain an 
advantage in the process of discussions and negotiations (Kaza, 2006: 262), which will often lead to a further hampering of the possibilities for open and sincere dialogue between stakeholders in planning processes. Further, Kaza notes that publicly acknowledging other stakeholders argumentation and thus publicly changing preference most often will lead to social and political costs, such as the loss of political capital and/or social rank for a stakeholder, and often leads to accusations of being fickle (Kaza, 2006: 262). As Brand \& Gaffikin note, the key question therefore becomes "...how can we enter the virtuous bootstrap loop without even an initial amount of trust? Expressed differently, how do we get to that 'big bang' moment that creates the foundations of trust?" (Brand \& Gaffikin, 2007: 291). As a tentative and partial solution to this problem Brand \& Gaffikin propose that planning processes should facilitate and provide arenas for non-adversarial discourse where value-systems can be articulated and shared strategic convictions can grow (Brand \& Gaffikin, 2007: 290). Framed in the language of agonistic political philosophy: what is needed are spaces where locked down antagonistic positioning, posturing and power-games can have a chance of being transformed into constructive agonistic debate and negotiations in which all stakeholders recognize each others' legitimacy and right to differ (see further Mouffe, 2000a, 2000b). So how can this transformation be achieved practically in planning processes, with regard to the potentially high risks and costs of those stakeholders who dare to engage in such a venture?

As a partial answer to the above question, Hillier (2002: 276) has highlighted the potentials of the public sphere(s) to fill such a function. Hillier, building on Cohen (1999), notes that the public sphere can be seen as consisting of a number of "minipublics", dialogical spaces that allow for confrontative argumentation as well as consensus formation in a process of forming public opinion(s). Important to note is that such spaces can be both formal and informal, and it has actually been suggested by Young (2001: 685) that these spaces might be most effective if they function outside the structures of official policy discussions. In a similar vein, Dryzek (2005), in line with Mackie (2006) and Fung (2003), highlights the importance of what he calls cold deliberative settings (Dryzek, 2005: 17). Dryzek notes that in "hot" and politically sensitive settings where the stakes are clearly on the table, 
such as in a planning process, it is hard for stakeholders to admit being persuaded by others' arguments, since this will entail a loss of credibility. Thus, in "hot" settings stakeholders are almost forced to have strongly formed views going into dialogue, views that will be hard to modify in a setting of this type. In contrast to the locked down positions of "hot" settings, "cooler" settings are often unofficial or advisory. Not as much is directly at stake in these forums, which opens up the possibility of minds being changed in the forum itself, without the risk of direct social and political costs to the stakeholder (here a parallel could be drawn to the notion of "third space" in psychoanalytic and postcolonial theory, cf. Bhabha \& Rutherford, 1990; Künstlicher, 2009). Cooler forums can therefore be seen as the type of dialogical spaces where stakeholders can afford to let their guard down, since nothing is directly at stake in these forums. Thus, "cool forums" describes the type of settings in which antagonistic posturing has a chance of being transformed into agonistic dialogue, where adversaries can dare to listen to each others' arguments, experiment with new perspectives and thoughts and even express understanding, bafflement or self-criticism without risking to incur potentially heavy losses of credibility (and with that, power). Thus, in the spirit of philosopher Peter Sloterdijk, we could perhaps claim that cool forums might actually aid us in generating an "atmosphere of democracy" (cf. Sloterdijk, 2005) through providing a space of the type that Heidegger called a Clearing [“Lichtung”] (Heidegger , 1971).

The Clearing, as both verb and noun, is in Heideggers terminology the opening up ("clearing") of a space ("a clearing") where we can explore who we are, and who we might become. Still, the Clearing is not a blank space, but could rather be understood as "an affective situation... [that] governs what can appear; what is concealed by what appears; what appears as that which it is not. It is not at all clear, but it shapes" (Garbutt, 2010: 38; cf. also Sloterdijk, 2009). So we mustn't be tempted to see cool forums, in the form of Clearings that generate an atmosphere of democracy, as mysterious vacuums in the overwhelming mass of society. Rather, these are situations "in the middle of things", into which people bring in all of who they are (including their opinions, interests, preconceptions and agendas), but where the conditions are such that it becomes possible to think, speak and act in new 
ways - thus generating a space that provides a potential for the new and emergent to take form (cf. van Tuinen, 2009: 107). These types of spaces can sometimes open up quite unexpectedly, but can also be deliberately designed and facilitated. Perhaps, borrowing the notion from Sloterdijk, we can regard the attempted engineering of cool forums in policy processes as an attempt to form bubbles, "structures that allow couplings" (Royoux \& Sloterdijk, 2005: 224), which at the same time constitute "material places... intervowen by discourses, forms, and social visions, in which we become (dis)oriented, in which our desires, pleasures, fantasies, memories, and hopes are folded and unfolded" (Castro Nogueira, 2009: 88; cf. Sloterdijk, 1998). Unfortunately, this type of "Clearings" or cool forums in the form of "bubbles" are often missing in planning processes, as most stakeholders realize that "the game is on" as soon as you sit down around the table with other stakeholders in a collaborative planning setting.

In relation to the above line of reasoning the question arises how planners can act to facilitate the construction of cool forums in otherwise "hot" planning processes, thus creating spaces for a more earnest and open dialogue between stakeholders. As Sandercock (2002: 6) notes, the achievement of such a climate in planning processes requires something more than the usual planner's tool-kit, namely a "method" that "complements but also transcends the highly rational processes typical of the communicative action model". In other contexts, Sandercock herself $(2004: 138,2005)$ has suggested planner-artist collaborations as one potential means of further developing the praxis of spatial planning by creating new forms of communication that can facilitate more earnest and open dialogue. Still, while Sandercock presents important and valuable insights into what artist involvement in planning processes can contribute (a new openness and dialogical sensitivity), there still exists a general lack of arguments as to why and how artists can contribute to opening up planning processes in ways that can be difficult to achieve without their involvement. Because of this I feel compelled to present at least a few tentative lines of reasoning concerning these questions. My argumentation will be based around the concept of verfremdungseffekt, which is a term I am appropriating from theatrical theory. 


\section{The merits of strangeness}

Landry (2000:179) has noted that one of the most powerful creative devices in planning processes is the art of "making the familiar strange, and the strange familiar", and this is exactly the idea of the verfremdungseffekt. The idea of the verfremdungseffekt has previously influenced urban and planning theory primarily through Marxist theorists, such as Lefebvre's ideas on the defamiliarization of the everyday (cf. Lefebvre 1988, 1991; Gardiner, 2004) and the Situationist concept of détournement (cf. Debord, 2004; Debord \& Wolman, 2006). ${ }^{4}$ The modern roots of the verfremdungseffekt-concept can be traced back to the literary critic Viktor Shklovsky(/Shklovskij) who belonged to the movement known as the Russian formalists. In a 1916 essay Shklovsky coined the Russian term "priem ostranenie", which crudely could be translated into making strange. In his essay Shklovsky argued that a major purpose of art is to make taken-for-granted situations and objects "unfamiliar" (Shklovskij, 1998: 16). Thus - through the work of defamiliarization - an audience is forced to look upon something previously perceived as well-known, assimilated and unproblematic with new eyes. According to Shklovsky, poetic and artistic language constantly contains "material obviously created to remove the automatism of perception; the author's purpose is to create the vision which results from that deautomatized perception" (Shklovskij, 1998: 19). As such - defamiliarization, as a deautomatization - is for Shklovsky the poetic art of provoking or "pricking the conscience" (Shklovskij, 1998: 16), or as psychiatrists Merton Gill \& Margaret Brennan has described it: "De-automatization is, as it were, a shake-up which can be followed by an advance

\footnotetext{
${ }^{4}$ With regard to the Marxist intellectual tradition it is important to remind ourselves of the difference between the Marxist concept of alienation, entfremdung, and the activity of verfremdung, defamiliarization. These two concepts are far too often conflated and confused under the label of "alienation" (cf. Jameson, 2000). Further adding to the confusion - Lefebvre, one of the initiators of the debate on the role of the concept of alienation (entfremdung) in the writings of Marx, has also written on the potentials of verfremdung and détournement in the combating of alienation (cf. Lefebvre 1939, 1988, 1991; Gardiner, 2004). Rather than confuse these two concepts, we must remind ourselves that for Brecht, the main proponent and developer of the verfremdungconcept, the purpose of verfremdung can be seen as the attempted reversal of alienation - entfremdung through the putting-into-doubt of the naturality and neutrality of an alienated state of life (cf. also Bloch, 1970). But, we have to remind ourselves, such a formulation of the merits of verfremdung relies on a
} 
or retreat in the level of organization... Some manipulation of the attention directed towards the functioning of an apparatus is necessary if it is to be de-automatized" (quoted in Deikman, 1966:329). As such, the idea of defamiliarization through art, as presented by Shklovsky, rests upon the conception that the audience stands in need of some sort of "aesthetic shock" to break him or her out of the anesthesia of their every day conceptions of the world (Robinson, 2008:81)

A parallel can here be drawn to political theorist Antonio Gramsci's use of the concept of "common sense". In Gramsci's usage this term defines those values, beliefs and ideas that are so deep seated among a particular group that they are taken for granted and ubiquitous, but in reality are historically and politically conditioned and therefore also thoroughly ideological and political (Grossberg, 1996; Gramsci, 2000; cf. Robinson, 2008: 108). Thus, to be able to bring Gramscian common sense up to the surface and enable discussion, self-reflection and re-evaluation of these deep seated presuppositions, individuals need help to become "strangers to themselves" (admittedly an allusion to the title of Kristeva, 1991), to be "defamiliarized" or have their everyday world "made strange" in the manner described by Shklovsky. This defamiliarization can be achieved through a verfremdungseffekt (alternatively translated as "estrangement effect", "alienation effect", "distancing effect" or "defamiliarization effect" - by Brecht often abbreviated simply as "V-effect"), a term coined by Berthold Brecht to describe both the effect of distancing/self-distancing and the artistic devices through which this effect can be achieved in communicating with an audience (cf. Jameson, 2000:40; and further Brecht, 1964). Frederic Jameson notes that through the verfremdungseffekt:

... the familiar or habitual is reidentified as the 'natural', and its estrangement unveils that appearance, which suggests the changeless and the eternal as well, and shows the object to be instead 'historical', to which may be added, as a political corollary, made or constructed by human beings, and thus able to be changed by them as well, or replaced altogether. (Jameson, 2000: 40)

subscription to a Marxist idea of reversible generalized human alienation, a conception of the world which is 
Thus, a verfremdungseffekt in art aims to achieve Gill \& Brennans "shake up", a cognitive dissonance amounting to the perplexity of mind and body that according to Vygotskij (1971) affects the human being as she encounters (great) art. This perplexity has the potential of generating a counterhegemonic, tectonic jolt that unsettles the taken-for-granted.

To pedagogically describe the V-effect, Brecht has used the imagery of a child whose mother remarries, which makes the child suddenly see her - not only as a mother - but also as a wife; or whose teacher is prosecuted, making the child suddenly see the teacher as a simple subject of criminal law rather than as a classroom authority. Through the recontextualization of a phenomenon in a new setting, the observer becomes estranged and defamiliarized from a phenomenon previously considered as self evident and well known, which forces the observer to a reconsideration of the phenomenon at hand. Thus, the V-effect also puts the spotlight upon the power of setting or "framing", already tentatively explored by Healey (for instance in Healey, 2006). A parallel can here be drawn to the gainful insights ANT-scholars have given us by highlighting the relevance of settings in relation to social performativity. For as Dugdale (1999) notes, seemingly mundane materials such as room arrangements, letterheads, vouchers and schedules all play a role in producing specific modes of subjectivity, for instance a "bureaucratic subjectivity". Peter Sloterdijk, reflecting on the preconditions of democracy, makes a similar point when he notes that the public sphere with deliberating citizens for its existence relies on "the construction of a space to contain them and in which the assembled persons are first able to assemble" (Sloterdijk, 2005: 948). Dugdale further notes that such material and immaterial "performative arrangements" constitute "modes of ordering" (Law, 1994) and thus confer certain limited agencies upon participants which are put into play by the arrangements themselves - not through some crude predetermination of courses of action, but rather through the setting of the stage and establishment of conditions for action in a certain arena or forum (Dugdale, 1999:120). In a similar vein, Latour (2005:195) discusses how 
material arrangements shape specific settings that facilitate a certain scripting of events, that is, creates the preconditions within a series of actions can/will unfold. Latour calls these material scripting arrangements structuring templates, in which "paper techniques and, more generally, intellectual technologies [are] as important as gears, levers, and chemical bonds" (Latour, 2005:196).

At this stage of the argumentation it is gainful to make a loop back to the above quotes from Healey and Sandercock where they plead for planning stakeholders to "stand back from their particular concerns, to review their situation, to re-think problems and challenges", to mentally "unhook" or "suspend... habits of being". What we can see, utilizing the concepts appropriated from Shklovsky and Brecht, is that what Healey and Sandercock are calling for is the defamiliarization or verfremdung of stakeholders from their habitual common sense presuppositions, as a first stage of forming a new, more open and earnest climate of dialogue than that which commonly permeates planning processes. Or as Jameson (2008: 47) describes the effects of verfremdung: "[w]hat history has solidified into an illusion of stability and sustainability can now be dissolved again, and reconstructed, replaced, improved, 'umfunktioniert'”. Also, in Robinson's (2008) reading of Shklovsky, this social transformation is the exact purpose of "making strange" through art or literature: "...the purpose of art for him is precisely to push the reader past language to a reworking not just of perception but of embodied participatory experience in general" (Robinson, 2008: 112, emphasis in original). Similarly, Robinson notes that for Brecht, the purpose of verfremdung is for the audience to become "coproducers of the transformative effects of estrangement" (Robinson, 2008: 238). Thus, it could be said that verfremdung, defamiliarization or deautomatization constitutes the (perhaps necessary) precondition for collective catharsis (cf. Vygotskij, 1971) and the development of those new, shared sensibilities among stakeholders that are described by Sandercock and Healey as necessary for the successful evolution of planning practice.

Following Latour and Dugdale, it could further be argued that one means of achieving such a verfremdungseffekt could be by shifting the material arrangements and thus "setting a new scene" 
for the stakeholders. This can partially be achieved through the arrangement or creation of a new physical environment to meet in, but also through shifting the "intellectual technologies" mentioned by Latour, such as creating a bounded context in which stakeholders are prodded into using a new and different language and different logics of reasoning (also see Healey, 2006; Sandercock, 1998), thus temporarily shifting the process of planning into a new "structuring template" with the hope of achieving permanent effects upon the dialogical climate of a planning process. The trick is, as always, how to achieve this shift. The tentative answer, touched upon above, is that art and artists perhaps can design and/or facilitate forums that can help shift these structuring templates for planning processes and stakeholders, an idea that will be further developed below.

\section{Verfremdung through art in planning processes}

In this section I will attempt to sum up, tie together and further develop the arguments presented above as to why art and artists can be helpful in advancing planning processes in ways that are difficult for planners and stakeholders to achieve on their own hand. The argument goes something as follows: Planning processes are often marred by locked-down positioning, strategic posturing and defensive attitudes among stakeholders creating a less than gainful climate for the creation of mutual understanding and open discussions and negotiations (cf. Plöger, 2004; Kaza, 2006; Brand \& Gaffikin 2007). But through the use of the verfremdungseffekt (cf. Brecht, 1964; Shklovskij, 1998; Jameson, 2000) and the creation of "strange places" that can function as "cool" bubbles (cf. Dryzek, 2003) by deviating from commonly established structuring templates for planning stakeholders and processes, stakeholders can be defamiliarized from established conventions and given the chance to reconsider their positions and experiment with new perspectives and thoughts without risking to incur losses of credibility, prestige and influence. As a result, this type of temporary shift of the planning process into a new structuring template (cf. Latour, 2005) can in the best of cases create grounds for the development of those new, shared sensibilities among stakeholders that are described by Sandercock (2002) and Healey (2006) as necessary for the successful evolution of 
planning practice. This would mean that, through activities in defamiliarizing cool forums, antagonistic posturing would have a chance of being transformed into fruitful, agonistic dialogue, where adversaries can dare to listen to each others' arguments, experiment with new perspectives and even express bafflement or self-criticism.

The summation above doesn't mention "art" or "artists" with a single word. So the question still appears to go begging relating to what art and artists specifically have to contribute to planning processes. And, in theory, shouldn't planners be able to achieve all of the above on their own hand, without having to involve art and artists in potentially messy and difficult collaborative projects? After all, there already exist a plethora of creative planning methods out there, which can be utilized by the planning practitioner to approach the planning enterprise in novel ways. And if we still see some unique merits in the verfremdung-approach, wouldn't it be enough to call for a new openness in planners' consciousness and the inclusion of verfremdung-techniques in planning education? My simple answer to this is: no. And why is this? To begin with, planners today often lack the necessary professional training and skills to be able to help their clients achieve defamiliarization. But this is a minor issue. The serious problem in this context is rather that the established professional role of the planner, that is: the type of utility that is generally expected to be delivered by planners in the eyes of clients and the general public, to a very high degree disables planners from achieving, or even attempting to achieve, V-effects on their own hand. In planning processes, professional planners are generally expected to behave as experts, to be sensible, and - if not rational - then at least prudent and measured in their discourse and behaviour.

Whether envisaged as a technical expert, a critical friend, or a knowledge mediator and broker, it is unavoidable that stakeholders expect planners to be straight-talking and problem-solving rather than strange and confusing (although, no matter how straight planners believe themselves to talk, confusion and estrangement is often the result anyway - but this is a completely different discussion). As a result of this, planners generally lack the mandate "to be strange" that is granted 
to artists through what could be called the artistic license. As a partial explanation of the concept of the artistic license, a parallel can perhaps be drawn to the political position of court jesters of medieval monarchs (with the clarification that no further similitude between contemporary artists and medieval jesters is implied beyond this limited and specific aspect). The court jester was historically a person employed to tell jokes and provide entertainment at the courts of European medieval monarchs. Although the established image of the court jester has not gone unchallenged (cf. Carlyon, 2003), it is generally believed that the role of the jester was not simply to amuse, but also to criticise the other members of court, including their masters (cf. Wallett, 1870: viii-ix). Sometimes court jesters were seen to be "natural fools" (in some aspect mentally challenged), but often they were rather considered to be "normal" individuals that by royal decree were granted the privilege of a "fool's license" to question and challenge power in a way that no regular courtier or royal councillor ever would dare, if not to risk their lives. The fool's license allowed court jesters to ask seemingly stupid questions and deliver superficially dumb comments that had the potential of creating effects of defamiliarization among the audience the comments or questions have been directed at, thus forcing a shift of perspectives and creating a potential for a radical reconsideration of the issues discussed. Thus, the court jesters could "tickle, coax and cajole their supposed betters" and through this behaviour "inspire expansive, self-enlarging gestures in their pupils" (Edmundson, 2000).

Just as the court jester of medieval times had a granted mandate to tell the truth to the king in a manner that no one else at the court would have the privilege to, the artist in today's society has a mandate to act in ways that no other agents of governance could afford themselves to do. So if we, as I here suggest, regard the artistic license as a contemporary analogy to the medieval fool's license, this would mean that artists - in contrast to professional planners - would possess a unique mandate to "make strange" in politically highly sensitive processes. In fact, with regard to the social role attributed to artists in (post)modern societies today, most of the time, nothing less is expected of them. Where planners are generally expected to be prosaic, that is - literally - to be straightforward 
and to make sense, nothing such is expected of artists, who are rather granted an "artistic license", a license to priem ostranenie - "make strange".

Further, the speech and actions of the planner, as a carrier and representative of expert knowledge, in most planning processes are seen by other actors as carrying political weight. This means that the speech and actions of the planner within the planning process is potentially politically dangerous and/or valuable to stakeholders. So when the planner speaks or acts within the process, stakeholders often see a need to be en-garde, thus generating a politically "hot" atmosphere, with all the risks of strategic posturing and power games that is attached to that type of deliberative setting. With regard to artists on the other hand, the situation is clearly different. Artists are generally not seen to carry direct political leverage in the same way as planners, which, in this context, is something gainful and creates an opportunity to generate a cooler deliberative atmosphere, as stakeholders most probably will not feel a need to be as careful in their relations with the artist as with the planner. Of course, this does not mean that we can delude ourselves into believing that artists are some sort of unpolitical agents of pure aesthetics, and because of this can act as politically blank projection screens for society's collective becoming. Rather, it means that the establishment of an artistic framing of an event creates the possibility for setting the scene in a different way than the planner generally has a mandate to do, which might create the conditions for a "cool" artistically framed bubble within otherwise "hot" (nominally) technical-rational, bureaucratic and/or politicaldeliberative processes, thus creating opportunities for participating stakeholders to be political and think politically in new ways, to ask new questions, and perhaps - find new answers.

So, to summarize this section: artists, in contrast to planners, could be said to have a clear mandate to conjure up strange and unfamiliar/defamiliarizing situations that in the best of cases can create a verfremdungseffekt among the audience or participants (in the case of planning, stakeholders) and there through enable them to look upon themselves and their situations with new eyes. In the case of planning processes, this would perhaps mean that artists might be able to help planners and 
stakeholders to at least partially cut themselves out of the bureaucratic-political planning loop, or structuring template, and face each other under new auspices. Thus, there exists an inherit value in itself in that the script, frame and template of artistic activity is something completely foreign to standard planning procedure; it is a strange space within otherwise (nominally) rational processes. It leaves artists in the planning process with a mandate to do things that planners will find difficulties achieving on their own: to create an out-of-the-ordinary experience for stakeholders that hopefully can provide openings that could otherwise be difficult to achieve.

Still, we have to remember that the corollary of openings is closure. As Campbell \& Marshall (2002) note, building on Harvey (2000), explorative or deliberative phases in a planning process must be followed by an "either/or" decision at some point or other, however indirect, since any decision to move the process on inevitably means not making a different decision/prioritization/agreement (cf. March \& Low, 2004). Even postmodernists, although inherently skeptical of closure which is generally seen as an exercise of symbolic violence (cf. Allmendinger, 2002), recognize that some form of "robust agreements" and "settlement of debates" is necessary within planning processes (Hillier, 2003). Even if closure is (and in the eyes of Hillier, should be) temporary, it has to be achieved in some format for organizational action to be possible (Hillier, 2007: 257). Following these insights, it is important that the use of artistic forums in planning processes should never be seen as a "fix all"solution. Rather, based on the rationale presented in this article (of course only one of many possible such), planner-artist collaborations can create unique possibilities within planning processes, but only in very specific parts of these processes, where new openings are in dire need. In other parts of the process, "moving on" through some form of closure or settlement is generally desirable and/or necessary, and most probably there are other methods and forums that are more suitable at these stages (cf. for instance Wates, 1996; Maguire, 1998; Segedy \& Johnson, 2000; Cars, 2001) . Most probably, in the final decision making stage of planning processes overtly "hot" political forums are to be preferred (and most usually legally required) for the decision making parts of the process 
instead of semi-formal or informal cool forums, as hot forums tend to provide for a higher degree of democratic transparency and accountability.

\section{A radical shift of scenery}

The following section presents an empirical investigation of one attempt to achieve new openings in planning processes through planner-artist collaboration. The purpose of this case-study is to confront the theoretical ideas presented in the article with an empirical material, and through relating the theoretical discussion to an empirical material, develop and problematize the theoretical line of reasoning explicitated above. In Sweden in 2007 a co-operation project was established between the Stockholm County Council Office of Regional Planning and Urban Transportation ("the planning office"), the Cultural administration of the Stockholm County Council and Konstfrämjandet - the national association for promotion of art, a semi-public organization for the promotion of art in society. Funding was provided for four artists to partake in the process of developing a new regional development plan for the Stockholm region, RUFS 2010. The artists were placed at the planning office for a one year period, from October 2007 to October 2008. During the first half year the artists conducted preparatory research concerning the practice and knowledge base of regional planning in Sweden and also participated as observers in all aspects of the daily routines at the planning office. During the last six months the artists developed and carried out their own project, in cooperation with planners and supporting staff from the planning office. The project was presented as an official knowledge generating and dialogue activity under the auspices of the planning office and an official input channel into the formulation of a new regional development plan for the Stockholm region. The artists chose the working title $A$ radical shift of scenery for their project. The concrete project which was focused on a workshop concept - was generated by the four artists and their independent project manager, and was later developed in dialogue with the management and staff of the planning office, and especially with the four planners of different specialization who would later participate in the project as process facilitators together with the artists. 
[INSERT FIGURE 1 HERE]

The artists temporarily transformed a regular three room apartment in an ordinary suburb of Stockholm into a "platform for ideas" or "black box" (in the theatrical sense of the term rather than the engineering sense of the term used for instance by Latour, 1987), that is - a room where anything can be staged. The idea was to - literally - open up a new space for rethinking the regional planning process. During a one month period over 200 regional and municipal politicians and public officials partook of the artists' workshop. Initially, all the walls of the apartment were painted completely black, and black wall-to-wall carpeting was installed. The reason for creating this workshop space in an ordinary residential apartment was two-fold: on the one hand the artists held a wish to create a connection between everyday life in the region and the sometimes quite lofty formulations of regional development planning, on the other hand they simply wanted to "get away from the well-known conference rooms and meeting agendas" (quoted from the artists own written account of the project). In one of the rooms a film loop presented the apartment the way it looked before the first workshop and before it, literally, became filled with the traces of discussions (see further explanation below).

A carrying idea of the workshop project was to create an opportunity and platform where the invited workshop participants were allowed and encouraged to make connections between their professional activities as stakeholders in a regional development process and more personal feelings and experiences. After introductory coffees, the workshop participants were divided into sub-groups that rotated between three workshop activities in the apartment. Each activity was facilitated by a combined planner-artist team. Following the workshop activities the sub-groups were rejoined for a standing meal of soup and bread (cooked by the previous day's workshop participants, see further below) and concluding discussions and reflections. The main focus of the programme was the three sub-group workshop activities named Agora, Subjective mappings and A sustainable soup 2030. In the Agora workshop participants were given an opportunity to hold an in-depth round-table 
discussion around a broad selection of concepts and terms. The artists described the workshop as a room of both doubts and possibilities where the multiple meaning of concepts and terms could be discussed unconditionally. The list of terms available for discussion were all central to the planning process, implicitly or explicitly, but often under-defined catchwords with a taken-for-granted meaning such as "growth", "identity" or "resource efficiency". Broader concepts such as "democracy" and "power" were also available. During the workshop, the task of noting down fragments and notes from the discussion on the walls of the room rotated among the workshop participants. Slowly, the walls grew into palimpsests of texts, fragments and quotes from the preceding discussions.

[INSERT FIGURE 2 HERE]

In Subjective mappings the participants carried out a number of swift mapping activities, centered on their personal life and everyday routines. These mappings formed the basis for a discussion on issues of place attractiveness and values. To shift perspectives from the technically and statistically advanced mapping techniques of professional planning practice, the artists decided to open up subjective perspectives that highlighted individual patterns of movement in space and the lifecycle in its full course. More or less random places play different roles in different periods of our lives. What values do they represent to us? Does the emerging regional plan make room for these values? The intention was to concretize the concept of "attractiveness" by linking it to issues of needs and wishes today and in the future through questions about what is attractive, and to whom?

Finally, in A sustainable soup 2030, participants were presented with all 58 regional commitments (planning directives) presented in the draft proposal of the new regional plan. The participants were then forced to prioritize among the regional commitments with the purpose of concocting a "sustainable soup" based on the question of what ingredients that are needed to reach the vision of a sustainable development in the region by the year 2030. Discussions emerged concerning unrenewable natural resources and limited economic resources, the investments needed and what 
end to start working in. Can the regional commitments be separated from each other or do they have to be treated as a package? What commitments are most urgent? What conflicts and synergies emerge? Through a clever color-coding scheme, the regional commitments were then translated into different categories of vegetables, and the participants were literally invited to work together to concoct a "sustainable soup" out of the regional commitments. The soup was then served to the participants of the following workshop, based on the idea that emerging generations always are presented with the results of the priorities and choices made by the generation before them.

[INSERT FIGURE 3 HERE]

\section{Reflections from participants in A radical shift of scenery}

This section is based on a number of sources of documentation from the workshop A radical shift of scenery. The workshop facilitators used log-books to record reflections and thoughts in immediate connection to the workshop occasions. After the project was finished individual interviews were also conducted with the workshop facilitators from the planning office and with workshop participants such as elected politicians and public servants from both the regional and municipal levels. A group discussion/interview with all the workshop facilitators including artists and planners, as well as supporting staff from the planning office, was also carried out. The documentation of the project is a very rich evaluation material, containing many hours of recorded and transcribed semi-structured interviews. In the context of this article I will therefore choose to focus solely on the parts of the material that can be directly related to the issues at hand. All direct quotes have been translated from Swedish by the author.

\section{"Fun and exciting"}

All of the interviewed workshop participants and process facilitators describe the experience of participating in the workshop in terms of having been "fun", "exciting" and "interesting". A recurring 
description is also "creative". One participant describes the workshop as containing elements of both "happening" and "serenity", which created a unique milieu.

"Free and open"

A number of participants stressed that the workshop facilitated a distinct sense of openness and freedom of expression. One participant, a municipal planner responsible for the municipality's input into the regional planning process (Planner $A$ ) explained that in her experience, there is a strong tradition in planning practice that is very strict on "right and wrong" and "afraid of change", which leads to a "limiting way of thinking". This limiting way of thinking doesn't encourage creativity and the testing of new practices, but in the eyes of Planner $A, A$ radical shift of scenery challenged this tradition through attempting to introduce new ways of opening up and challenged the old, established ways of going about things in planning practice. One of the process facilitators in the workshop, who works as a planner at the regional planning office (Process facilitator $B$ ) remarked that it appeared as if most participants really saw the workshop as an opportunity to "air questions" and "hear what others think". She further noted that "we had interesting trains of thought about priorities and about important questions, and about what questions that were [normally] not given a voice".

\section{"Unexpected and different"}

It is clear that the participants in A radical shift of scenery perceived the workshop to be a unique and novel way of working in regional development processes, which established conditions for dialogue that generated openings and opportunities. For instance Regional development advisor $C$ described the workshops as a clever way of "going the back-way" to bring up important issues and described it as a way of getting people to "meet and think outside the frame". She further noted that in her current job that was hard to achieve, that there "is no place for reflection" and that "creative activities" require an "extra space". She further reflected upon the role of the artists in creating this place of reflection: 
I guess an artist or two are needed to help us think outside the frame. We walk around inside our little box and need to think outside of that which we walk around in every day. We need to create meeting places. Meeting-places already exist, but the problem is that they are so one-dimensional. It is the same kind of people who meet there, so you keep inside your box anyway! What the apartment did was that very different people met there. It became real meetings, dynamic meetings where you were forced to take sides. - Regional development advisor C

An elected municipal political representative who was also a member of a county planning board (Politician D) stated that to him, it appeared as if the workshop was "lacking all the frames of how things are usually done". He noted that municipal representatives often are very limited in their repertoire: "We know what we can say, especially under the party whip. But in the black apartment, the whip was missing". In Agora, which he ambivalently described as a "forum where people just scribbled on the walls whatever people spit out of themselves, without having to concretize", participants were allowed to think freely, which is something that otherwise "never materializes".

According to Politician $D$ the setting in the workshop created a climate for discussions that provided a clear rupture from the ordinary routine. Normally, he reflected, "[t]here is a reward system for politicians that rewards conflict. You strive to create differences because that is what the voters reward. That hampers the creative dialogue". But in the apartment the setting was so different that new opportunities for dialogue opened up. To illustrate his point Politician $D$ referred to the political situation in his home municipality, which at the time had been plagued by a lot of recent political strife and shifting alliances:

Of course it is difficult when your pal goes over to the opposition. Conflicts and irritations constantly erupt. Seen from that context, this meeting [A Radical Shift of Scenery] meant that we could let go of our positioning and roles for a moment. For four hours we could return to how we used to talk together. So that was good, but perhaps that wasn't what you had brought us there for! - Politician D 
Quite a few of the workshop participants and process facilitators mentioned the set up of the physical space for the workshop as part of the explanation as to why it became such a success in creating a new climate for dialogue. Process facilitator $B$ pointed out the relevance of the creation of a new kind of space for dialogue, noting that "there is a point in going to a different place" and that "something happens when you are relieved of the ordinary conference room." In her eyes, just getting the participants onto a commuter's train into the suburbs instead of into the regional planning office in central Stockholm made an important difference.

Process facilitator $E$, also reflected that “it wouldn't have been the same if we would have been sitting in a municipal administrative building", and that she also was surprised at how well the project turned out, considering how different the set-up was from established dialogue forms in regional planning processes:

I had a hard time imagining the head honchos standing there cutting [vegetables] in the kitchen. It turned out not to be a problem. A few of the highly profiled politicians turned up. I only heard of one politician who was suspicious initially, but it soon passed. - Process facilitator $E$

\section{"Insubstantial and frustrating"}

Notwithstanding the general positive judgments delivered from most participants and process facilitators regarding the workshop and the unique openings for dialogue that it was seen to deliver, there still existed a feeling of unease in the aftermath of the project among a number of participants. Process facilitator $B$ found the artistic symbolism of the project to be "too subtle" at many times. Along the same lines, Planner $A$ noted that the elected representatives from her municipality declined to participate in the workshop. She suspected that the reason for this was that the workshop seemed "a little too abstract" and that the politicians in her municipality "have been very concrete and object-focused". 
Regional development advisor $C$, who was very positive to the project in general, was nevertheless disappointed since she felt that the important lines of reasoning developed in the workshop were not given enough time to be fully followed through. In her eyes "more structure" and "a clearer idea" might have contributed to producing more concrete results from the open and inspired discussions that emerged in the workshop. Also Politician $D$ expressed a frustration and disappointment with the lack of concrete results from the workshop. His lasting impression was instead one of "vagueness", and even though the workshop was "very playful and creative" and generated a "completely free dialogue" which managed to liberate itself and "let go of all the formal guidelines that normally exists within politics", it was still frustrating. He asks himself what the participants brought with themselves from the workshop: "an impression, but nothing more". Something was missing that could be turned into concrete formulations, and therefore he could not see how this activity could influence the regional planning process in any fundamental way:

I was taken by the meeting itself. I thought it was really good. But what comes out of it? How does it affect us in our stances? We have met many times since then but never again spoken about that event. - Politician D

Politician $D$ participated in the workshop in his role as elected municipal representative. When the question of participating in the workshop was brought up on a regional planning board where he was a member he recommended his colleagues to decline the invitation since he didn't find the workshop suitable in that context. Politician D concluded that the workshop made "a good impression" on him because of the "creative milieu and the out-of-the-ordinary set up". Still, he found an urgent need of a "stage two" of concretization: "What you did was to release the mind and the tongue, but for it to stick one needs something more". This created a sense of frustration. He felt that there was "some sort of consensus discussion" and that the participants "could have arrived at a common standpoint", but the common standpoint never materialized: 
I think this way of working with the black apartment was good, but you have to strive towards getting to some sort of conclusion. So that you remember where the conversation reached. - Politician D

\section{Openings and closure: a concluding discussion}

The lack of resistance from participants almost shocked me. Only once someone said "what is this supposed to be good for?" Otherwise everybody was set on engaging on the existing premises. Honestly I am surprised... There were very few crossed arms.

The format has a great part in it, I think. It is quite relaxing to be on your feet peeling potatoes while you are discussing something very important. An unusual format makes it harder to get stuck in ordinary political bickering.

- Excerpts from the planner-artist evaluation discussion of A radical shift of scenery

The pioneering planner-artist collaboration project $A$ radical shift of scenery could be said to have been exploring and stretching the grey zone or "third space" between art and public processes such as spatial planning. This processual art project aimed at providing an out-of-the-ordinary environment that generated possibilities for new openings for stakeholders in a regional planning process. The project has generally been labeled as a success. It has featured in a number of seminars and exhibitions and has created important communication channels between the wider art and planning communities. In this particular case it also created the grounds for a prolonged and expanded cooperation between the involved artists and the planning institution in question. ${ }^{5}$ Still, it remains to be seen whether this will in turn lead to an institutionalization of planner-artist collaboration at the planning office, or whether the collaboration will remain in a capricious project form which is only partly integrated in the on-going activities of the planning office.

\footnotetext{
${ }^{5}$ So far, the collaboration between the planning office and the artists has, in addition to the "Radical shift of scenery"-workshops, also resulted in the production of two poster sets, one video, two exhibitions and a book. A new workshop/exhibition collaboration with two of the "Radical shift of scenery"-artists is also planned for 2011.
} 
In the aftermath to the project both planners and artists expressed a slight surprise over the felt success of the project. The general feeling was that participants in the workshops became very engaged and that the "black apartment" (as the workshop was called by participants) created openings for the participants to see the planning process and the emerging regional plan with new eyes. The process facilitators felt that, even though working within a notoriously consensus-seeking planning culture such as the Swedish, participants discussed openly, notwithstanding clear differences in values, and still managed to skirt the lure of reductionist consensus-seeking. All the interviewed workshop participants in one way or the other stressed that the workshop occasion became a space where political opponents who in their every day environment were locked into antagonistic contestation and posturing for a moment were able to step outside of their regular roles and transform their debating into dialogue.

Many of the participants also attributed the openings that were generated in the workshops to the difference of the situation from an ordinary planning situation. A number of participants also highlighted the role played by the specific physical space created in the project, that the strangeness of this space liberated participants from the constraints of their every day professional roles and subjectivities. Thus, it becomes obvious that one can conclude that processes of defamiliarization and verfremdung were at work in the project workshops. These processes generated a destabilization of established conceptions and created a space for reconsiderations and dialogue. Still, we must not fall to the temptation of describing the workshop situation as the creation of an empty space or some sort of collective tabula rasa, from which some sort of ex nihilo or ex natura collective consciousness or community was fostered. Rather, we can perhaps more gainfully grasp the workshop situation as the generation of a temporary Sloterdijkian "bubble", formatted so as to prompt a specific modality and manner of speech, into which all the participants - including the planners and the artists - brought themselves, their opinions, interests, preconceptions and agendas - but where the atmosphere of the bubble and the scripting of the situation enabled the participants to look upon themselves and others, and speak about themselves and others in ways that might have 
been difficult to achieve in many other situations and atmospheres. It also appears as if the discussions in the workshops unearthed some of the strife of planning processes, that according to Plöger (2004) is inherit to the same. By bringing this strife to the surface, but without attempting to steer it into a consensus, frustration was created among participants. At the same time, the "cool" form of the artistic project generated an opening whereby locked-down antagonistic posturing could be transformed into fruitful, agonistic dialogue.

Nonetheless, for many of the participants, being able to think in new ways simply wasn't enough. From their perspective, this simply couldn't be the aim of a planning activity. Instead, they yearned for closure, to bring the planning process "forward". In the follow-up interviews to the workshop, some participants voiced a frustration with regard to a perceived lack of direct impact of the workshop activities upon the formal drafting of the regional development plan and the municipalities' and agencies' position papers ('remissvar') on the preliminary draft of the plan. While the participating artists and most of the process facilitators felt that the value of the project was to open up a space of questioning or "doubts and possibilities" - simply to provide openings - at least some workshop participants appear to have been frustrated by the absence of a final consensus or concrete and tangible results to point to, that is - the lack of closure. It might even be said that some of the workshop participants appear to have experienced the workshop situation as that which Thrift (2009:123), following Weber (2008: 175) describes as a "passage-way, perhaps, but one that is not going anywhere" ${ }^{\prime \prime}$. This frustrating lack of closure even appears to have generated ambivalence about the value of the project. Such ambivalence can be fruitful when it results in deepened reflection instigated by verfremdung. At the same time it creates practical risks. If participants become too uncomfortable with this feeling of defamiliarizing and destabilizing openings and the lack of closure,

\footnotetext{
${ }^{6}$ It should be noted though, that in the context of Thrift's article this phrase appears to be positively connoted, while for the experience of the group of workshop participants being discussed here - those that lamented the lack of closure - this was an ambivalent or even negative experience.
} 
this can create bad-will to the degree that difficulties are raised for future planner-artist collaborations to be included in public planning processes.

One of the possible conclusions that can be drawn from this is that another lack in the project appears to have created this yearning for closure, and that is the lack of an articulated discussion on the values inherit in providing openings, such as those that can be associated with planner-artist collaborations aimed at achieving a defamilarization of stakeholders, without necessarily providing a corresponding closure in the same forum. Hopefully, this article can provide one small step in the articulation of such a justification ground for future planner-artist collaborations. Relating back to the introduction of this article, I hope that the article demonstrates that one of the most potent effects that are achievable by involving art [konst] in the planning process is the production of a potentially very fruitful "strangeness" [konst-ighet], a strangeness that can provide otherwise hard-to-achieve openings for stakeholders and unlock new perspectives and possibilities. Thus, practical possibilities can be opened up as stakeholders are enabled to find new perspectives and grounds for dialogue without running the risk of losing prestige or power, and without being coaxed into consensus. At the same time practical risks are also generated. One of the most serious of these risks is probably the creation of too intense a feeling of frustrating defamiliarization, without offering closure for the participants, and thus generating negative attitudes towards processual art as a phenomenonwhich in turn might seriously undermine the perceived legitimacy of the whole idea of bringing artists into the planning process. Balancing the creation of openings and closure in this context is probably an extremely difficult stunt to pull off. Perhaps, one way to creating some of the preconditions for achieving this is to further develop and communicate our understanding of how and why art is such a powerful tool in public processes such as spatial planning.

One possible explanation for the sense of frustration experienced by some of the participants as a result of the processual art project discussed in the article is the lack of an established way of measuring the outcome of processual art and other defamiliarizing activities in planning processes. If 
we regard the outcome of this type of activities generally as being some form of sensitization (Hache \& Latour, 2010; cf. Rorty, 1989) or heightened ability for affectivity (cf. Thrift, 2004, 2007; cf. Latour, 2004), perhaps what we lack is a purposeful and accepted metrology: a way of measuring the important but still - in the eyes of many - far too intangible outcomes of processual art projects (Latour, 1987, 2005; cf. Hinchliffe et al, 2007). Perhaps we need to develop and establish completely new ways of evaluating not only the effect but also the affect(ivity) of planning activities (cf. Faludi, 2000, 2006).

To conclude, planner-artist collaborations are obviously deserving - and in need of - further attention and engagement, both within planning practice and academic planning research. Not only do we need to learn more about the specific outcomes of concrete collaboration projects and activities, but other interesting venues for future investigation might also be the consideration of how the formatting of projects affect their possible outcomes, the further exploration of the spheres of (sometimes unconscious, non-communicated and/or conflicting) expectation that surround planner-artist collaborations; and also to explore the metrologies and normativities that consciously or unconsciously are being invoked in the formatting and evaluation of planner-artist collaborations.

\section{Acknowledgements}

I wish to thank Ann Magnusson, who compiled some of the background material used to write this article, and who generously made this material available to me. I also wish to thank the planners and artists who were involved in the "Radical shift of scenery"-project. Emma Stenström, Susan Brockett and Krister Olsson deserve ample credit for having taken the time and energy to provide me with insightful comments and suggestions on an earlier version of the text. Two anonymous referees contributed with very helpful and constructive comments that greatly improved the article. 


\section{REFERENCES}

Allmendinger, P. (2002) Towards a Post-Positivist Typology of Planning Theory, Planning Theory, 1(1), 77-99.

Bauman, Z. (1973) Culture as praxis. London: Routledge \& Kegan Paul

Benhabib, S. (1992) Situating the self. Cambridge: Polity Press.

Bhabha, H. K. \& Rutherford, J. (1990) Third Space: Interview with Homi Bhabha. in Rutherford, J., (Ed) Identity: community, culture, difference, pp 207-221. London: Lawrence \& Wishart.

Bianchini, F. \& Santacatterina, L. (eds) (1997) Culture and neighbourhoods. vol. 2, A comparative report. Strasbourg: Council of Europe.

Bloch, E. (1970) "Entfremdung, Verfremdung": Alienation, Estrangement, The Drama Review: TDR, 15(1), 120-125.

Bourdieu, P. (1993) The field of cultural production: essays on art and literature. New York: Columbia University Press.

Brand, R. \& Gaffikin, F. (2007) Collaborative Planning in an Uncollaborative World, Planning Theory, 6(3), 282-313.

Brecht, B. (1964) Alienation effects in Chinese acting, in J. Willett (ed) Brecht on theatre, pp 91-99. New York: Methuen.

Campbell, H. \& Marshall, R. (2002) Utilitarianism's Bad Breath? A Re-Evaluation of the Public Interest Justification for Planning, Planning Theory 1(2), 163-187.

Carlyon, D. (2003) The trickster as academic comfort food, The Journal of American Culture 25(1-2), $14-18$.

Cars, G. (2001) Charette: tre åkturer med "den lilla kärran". Stockholm: Royal institute of technology, Department of Regional Planning.

Castro Nogueira L. (2009) Bubbles, globes, wrappings, and plektopoi: Minimal notes to rethink metaphysics from the standpoint of the social sciences, Environment and Planning $D$ : Society and Space, 27(1), 87-104.

Cohen, J. (1999) Does voluntary association make democracy work?, in Smelser, N. \& J. Alexander (eds) Diversity and its Discontents, Princeton: Princeton University Press.

Dang, S. R. (2005) A Starter Menu for Planner/Artist Collaborations, Planning Theory \& Practice, 6(1), 123-126.

Debord, G. (2004) The society of the spectacle. London: Rebel press, 2004.

Debord, G. \& Wolman, G. J. (2006) A user's guide to détournement, in K. Knabb (ed) Situationist international anthology, Berkeley: Bureau of Public Secrets. 
Deikman, A. J. (1966) Deautomatization and the mystic experience, Psychiatry, 29, 324-338.

Dryzek, J. (2003) Deliberative democracy in divided societies: Alternatives to agonism and analgesia, Political Theory 33(2), 218-242.

Dugdale, A. (1999) Materiality: juggling sameness and difference, in J. Law \& J. Hassard (eds) Actor Network Theory and after, pp 113-135. Oxford: Blackwell.

Edmundson, M. (2000). Playing the fool, New York Times Books, 2000/04/02.

Evans, G. (2001) Cultural planning: an urban renaissance? London: Routledge.

Faludi, A. (2000) The performance of spatial planning, Planning practice and research, 15(4), 299-318.

Faludi, A. (2006) Evaluating plans: The application of the European Spatial Development Perspective, in E. Alexander (ed) Evaluation in planning: evolution and prospects, pp 119-146. Aldershot: Ashgate.

Florida, R. L. (2005) Cities and the creative class. New York: Routledge.

Flyvbjerg, B. (1998) Rationality and power: democracy in practice. Chicago: University of Chicago Press.

Fung. A. (2003) Recipes for public spheres: Eight institutional design choices and their consequences, Journal of political philosophy, 11(3), 338-367.

Gardiner, M. (2004) Everyday utopianism: Lefebvre and his critics, Cultural Studies, 18(2), 228-254.

Gordon, M. (2005) ...A View from the Pavement. Planning Theory \& Practice, 6(1), 119-123.

Garbutt, R. (2010) The Clearing: Heideggers Lichtung and the Big Scrub, Cultural Studies Review, $16(1), 27-42$.

Gramsci, A. (2000) The Gramsci reader: selected writings, 1916-1935. New York: New York University Press.

Gray, C. (2004) Joining-Up or Tagging On? The Arts, Cultural Planning and the View From Below, Public Policy and Administration, 19(2), 38-49.

Grossberg, L. (1996) History, politics and postmodernism: Stuart Hall and cultural studies, in Morley, D. \& K.-S. Chen, (Eds) Stuart Hall: critical dialogues in cultural studies, pp 151-173. London: Routledge.

Hache, E. \& Latour, B. (2010) Morality or moralism? An exercise in sensitization, Common Knowledge, 16(2), 311-337.

Harlan, D. (1997) The degradation of American history. Chicago: University of Chicago Press.

Harvey, D. (2000) Spaces of Hope. Berkeley: University of California Press.

Healey, P. (2006) Collaborative planning: shaping places in fragmented societies, 2nd edition. Basingstoke: Palgrave Macmillan 
Heidegger, M. (1971) Poetry, language, thought. New York: Harper \& Row.

Hillier, J. (2002) Shadows of power: an allegory of prudence in land-use planning. London: Routledge.

Hillier, J. (2003) Agon'izing Over Consensus: Why Habermasian Ideals cannot be 'Real', Planning Theory, 2(1), 37-59.

Hillier, J. (2007) Stretching beyond the horizon: a multiplanar theory of spatial planning and governance. Aldershot: Ashgate.

Hinchliffe S., Kearnes M. B., Degen M. \& S. Whatmore (2007) Ecologies and economies of action: Sustainability, calculations, and other things, Environment and Planning A, 39(2), 260-282.

Jameson, F. (2000) Brecht and method. London: Verso.

Jensen, O. B. (2007) Culture Stories: Understanding Cultural urban Branding, Planning Theory, 6(3), 211-236.

Kaza, N. (2006) Tyranny of the Median and Costly Consent: A Reflection on the Justification for Participatory Urban Planning Processes, Planning Theory, 5(3), 255-270.

Kristeva, J. (1991) Strangers to ourselves. London: Harvester Wheatsheaf.

Kunzmann, K. R. (2004) Culture, creativity and spatial planning, Town Planning Review, 75(4), 383-

404.

Künstlicher, R. (2009) The psychoanalytic situation as a play situation: exploration of a multi-faceted clinical situation. Stockholm: Stockholm University Department of Education.

Kwon, M. (2004) One place after another: site-specific art and locational identity. Cambridge, Mass.: MIT Press.

Landry, C. (2000) The creative city: a toolkit for urban innovators. London: Earthscan.

Landry, C. (2005) 'Urban Acupuncture', Planning Theory \& Practice, 6(1), 117-118.

Latour, B. (1987) Science in action: how to follow scientists and engineers through society. Cambridge, Mass.: Harvard University Press.

Latour, B. (2004) How to talk about the body? The normative dimension of science studies, Body and Society, 10(2/3), 205-229.

Latour, B. (2005) Reassembling the social: an introduction to actor-network-theory. Oxford: Oxford University Press.

Law, J. (1994) Organizing modernity. Oxford: Blackwell.

Lefebvre, H. (1939) Nietzsche. Paris: Editions sociales internationales. 
Lefebvre, H. (1988) Toward a leftist cultural politics: Occasioned by the centenary of Marx's death, in C. Nelson \& L. Grossberg (eds), Marxism and the interpretation of culture. Urbana: University of Illinois Press.

Lefebvre, H. (1991) The production of space. Oxford: Basil Blackwell

Mackie, G. (2006) Does democratic deliberation change minds?, Politics, Philosophy \& Economics 5(3), 279-303.

Maguire, T. (1998) Giving the public its day: how three pilots have used different forms of charettes to enliven community involvement efforts. New Brunswick: Institute for responsible management.

March, A. \& Low, N. (2004) Knowing and Steering: Mediatization, Planning and Democracy in Victoria, Australia, Planning Theory 3(1), 41-69.

Markusen, A. \& King, D. (2003) The Artistic Dividend: The Arts' Hidden Contributions to Regional Development. Minneapolis, MN: University of Minnesota, Humphrey Institute of Public Affairs.

Miles, M. (1997). Art, space, and the city: public art and urban futures. London: Routledge.

Miles, M. (2004) Urban avant-gardes: art, architecture and change. London: Routledge.

Mouffe, C. (2000a) Deliberative democracy or agonistic pluralism? Vienna: Institute for Advanced Studies.

Mouffe, C. (2000b) The democratic paradox. London: Verso.

Pinder, D. (2005) Arts of urban exploration, Cultural Geographies, 12(4), 383-411.

Pinder, D. (2008) Urban interventions: art, politics and pedagogy, International Journal of Urban and Regional Research, 32(3), 70-76.

Pløger, J. (2004) Strife: Urban Planning and Agonism, Planning Theory, 3(1), 71-92.

Rendell, J. (2006). Art and architecture: a place between. London: I.B. Tauris.

Robinson, D. (2008) Estrangement and the somatics of literature: Tolstoy, Shklovsky, Brecht. Baltimore: Johns Hopkins University Press.

Rorty, R. (1989) Contingency, irony, and solidarity. Cambridge: Cambridge University Press.

Royoux, J. C. \& Sloterdijk, P. (2005) Foreword to the theory of spheres. In M. Ohanian \& J. C. Royoux (eds) Cosmograms, pp 223-240, New York: Lukas \& Sternberg.

Sandercock, L. (2002) Practicing Utopia: Sustaining Cities, DISP 148, 4-9.

Sandercock, L. (2003) Cosmopolis II: Mongrel cities of the $21^{\text {st }}$ century. London: Continuum.

Sandercock L. (2004) Towards a planning imagination for the $21^{\text {st }}$ century, Journal of the American Planning Association, 70(1), 133-141. 
Sandercock, L. (2005) Interface: A New Spin on the Creative City: Artist/Planner Collaborations, Planning Theory \& Practice, 6(1), 101-103.

Sandercock, L. (1998) Towards cosmopolis: planning for multicultural cities. Chichester: John Wiley \& Sons.

Sarkissian, W. (2005) Stories in a Park: Giving Voice to the Voiceless in Eagleby, Australia, Planning Theory \& Practice, 6(1), 103-117.

Segedy, J. A. \& Johnson, B. E. (2000) The neighbourhood charette handbook. Louisville: University of Louisville.

Shaw, K. (2005) ‘Don't Try This at Home', Planning Theory \& Practice, 6(1), 126-128.

Shklovskij, V. (1998) Art as Technique, in Rivkin, J. \& M. Ryan, (Eds) Literary Theory: An Anthology, pp 17-23. Oxford: Blackwell.

Sloterdijk, P. (1998) Sphären: Mikrosphärologie. 1, Blasen. Frankfurt am Main: Suhrkamp.

Sloterdijk, P. (2005) Atmospheric Politics, in Latour, B. \& P. Weibel Making things public: Atmospheres of democracy, pp 945-951. Karlsruhe: ZKM.

Sloterdijk, P. (2009) Rules for the Human Zoo: a response to the Letter on Humanism, Environment and Planning D: Society and Space, 27(1), 12-28.

Thrift N. (2009) Different atmospheres: Of Sloterdijk, China, and site, Environment and Planning D: Society and Space, 27(1), 119-138.

Thrift, N. (2004) Intensities of feeling: Towards a spatial politics of affect, Geografiska Annaler B, 86(1), 57-78.

Thrift, N. (2007) Non-representational theory: Space, politics, affect. Abingdon: Routledge.

van Tuinen S (2009), Air conditioning spaceship earth: Peter Sloterdijk's ethico-aesthetic paradigm, Environment and Planning D: Society and Space, 27(1), 105-118.

Vygotskij, L. S. (1971) The psychology of art. Cambridge, Mass.: MIT Press.

Wallett, W. F. (1870) The public life of W. F. Wallett: The Queen's jester. London: 1870.

Wates, N. (2000) The community planning handbook. London: Earthscan.

Weber, S. (2008) Benjamin's-abilities. Cambridge, Mass.: Harvard University Press.

Young, G. (2008) The Culturization of Planning, Planning Theory, 7(1), 71-91.

Young, I. M. (2001) Activist challenges to deliberative democracy, Political Theory, 29(5), 670-90. 